\title{
Intrathecal midazolam for prevention of nausea and vomiting during and after cesarean section under spinal anaesthesia
}

\author{
Amol Singam ${ }^{1}$, Arpita Jaiswal ${ }^{2,}$, Rashmi Deshpande $^{3}$, Tapan Dhumey ${ }^{4}$ \\ ${ }^{1,2}$ Professor, ${ }^{3}$ Professor \& HOD, ${ }^{4}$ Resident,,${ }^{1,4}$ Dept. of Anaesthesia, ${ }^{2}$ Dept. of Obstetrics and Gynecology, ${ }^{3}$ Dept. of Cardiac \\ Anaesthesia, Jawaharlal Nehru Medical College, Sawangi(M), Wardha, Maharashtra, India
}

*Corresponding Author:

Email: drarpitajaiswal@gmail.com

Received: $08^{\text {th }}$ August, 2017

Accepted: $25^{\text {th }}$ October, 2017

\begin{abstract}
Introduction: Relevant incidences of nausea-vomiting during and immediately after cesarean section in spinal anesthesia are found to be high. Effectiveness of intrathecal midazolam $(2 \mathrm{mg})$ as an adjuvant to bupivacaine on the incidence and severity of intraoperative and immediate postoperative nausea and vomiting was investigated in the present study.

Materials and Methods: A randomized, controlled, double-blind study was conducted in 120 healthy women (ASA Physical status I and II) scheduled for elective cesarean section under spinal anesthesia. Parturients were randomly divided into two equal groups of 60 each. Group M(study group) -Patients received $10 \mathrm{mg}(2.0 \mathrm{ml})$ of $0.5 \%$ hyperbaric bupivacaine combined with $2 \mathrm{mg}$ $(0.4 \mathrm{ml})$ midazolam intrathecally and Group C (control group)- $10 \mathrm{mg}(2.0 \mathrm{ml})$ of $0.5 \%$ hyperbaric bupivacaine combined with 0.4 $\mathrm{ml}$ normal saline intrathecally. Assessment of the patients were done for incidence of nausea-vomiting, hemodynamic effects and occurrence of adverse effects during cesarean section and during first 6 hours after the operation.

Results: Incidence of emetic symptoms in Group M were significantly lower than Group C (15\% vs 63.34\%, p<0.05). There were no clinically serious adverse events observed in any of the groups. All neonates had APGAR scores more than 8 at one and five minutes.

Conclusion: Intrathecal midazolam as an adjuvant to Bupivacaine is associated with lower incidence of nausea and vomiting with no neonatal adverse effects.
\end{abstract}

Keywords: Nausea, Vomiting, Intrathecal midazolam, Spinal anesthesia, Cesarean section.

\section{Introduction}

The most commonly used anesthesia technique in cesarean sections is spinal anesthesia, this is due to its economical value, the administration is easy to execute, very effective, the rate of failure is very low, there is no systemic local anesthetic toxicity and the most important factor that it has a high rate of maternal satisfaction. ${ }^{1}$ Surgeries done under spinal anesthesia are associated with high incidence of nausea-vomiting and is an annoying problem to all concerned. It's always distressing for the patient, and might show some increment in the risk of aspiration of gastric contents. ${ }^{2}$ The etiological factors of intraoperative nausea and vomiting during cesarean section are visceral pain, hypotension, vagal stimulation and uterotonic drugs. Some other factors that play a key role are the patient's demographic data and anesthetic technique. ${ }^{3}$

Traditional drugs used in cesarean section as an antiemetics are associated with side effects. metoclopramide can cause impaired taste, smell, hot flushes and tardive dyskinesia. Similarly, droperidol cause extra pyramidal symptom, dysphoria and may induce tachycardia. $5 \mathrm{HT}_{3}$ antagonist like ondansetron, granisetron, palonosetron can be effectively used for reducing nausea and vomiting with low incidences of side-effects but they are highly expensive and can also transfer into breast milk. ${ }^{4-6 .}$
Midazolam (benzodiazepine) is a water soluble and a potent short acting drug. It has been used for potentiating the analgesic effect of local anaesthetic in neuro-axial blockade. Its antinociceptive effect is mediated through benzodiazepine-GABA receptor complex within the spinal cord. It acts by reduces excitatory GABA-mediated neurotransmission in interneurons \& increases the threshold for pain. ${ }^{7}$ Antiemetic effect of midazolam could be explained by its action at the chemoreceptor trigger zone reducing synthesis, release and postsynaptic effect of dopamine. ${ }^{8}$ Administration of low dose of iv midazolam as premedication prior to caesarean section reduces anxiety of mother ,without any adverse effect on newborn. ${ }^{9}$

As traditional antiemetic are associated with side effects mentioned above, to find an alternative approach to antiemetic therapy this prospective, randomized, double blind study was planned by using midazolam (2mg) as an adjuvant to bupivacaine in spinal anaesthesia. The primary objective of this study was to evaluate the effect of intratechal midazolam for reduction in incidence of intraoperative and immediate postoperative nausea and vomiting. The secondary objectives were to evaluate and compare the hemodynamic effects, incidence of adverse events (sedation, respiratory depression, shivering and hypotension) and its effect on neonatal outcome. 


\section{Materials and Methods}

This prospective, randomized, double blind study was practically conducted in the Department of Anesthesiology, Acharya Vinoba Bhave Rural Hospital, Sawangi(M), Wardha from Aug 2013 to Aug 2015. Authentic protocol was approved by the medical ethics committee. Informed written consent was obtained from 120 parturients belonging to American Society of Anesthesiologists (ASA) physical status I and II scheduled for elective term cesarean section under spinal anesthesia and they were included in this study. Parturients with contraindication to spinal anesthesia, allergy to the local anesthetics or midazolam were excluded from the study.

Random allocation of the patients was made by a random number table (60 patients in each group). Neither the anesthesiologist nor the parturient herself were aware of the drugs; evaluation of incidences of emetic symptoms was done by blinded investigator. In Operation Theater, 20G intravenous cannula was inserted into a forearm vein and ringer lactate $15 \mathrm{ml} / \mathrm{kg}$ was an administrated. Routine monitors such as pulse oximeter, non-invasive blood pressure and ECG were attached and baseline values were noted. Spinal anesthesia was performed at $\mathrm{L}_{3}-\mathrm{L}_{4}$ interspaces with $25 \mathrm{G}$ Quincke needle in left lateral position. The patients received $10 \mathrm{mg}(2.0 \mathrm{ml})$ of $0.5 \%$ hyperbaric bupivacaine combined with $2 \mathrm{mg}(0.4 \mathrm{ml})$ midazolam in Group M as a study group and $10 \mathrm{mg}(2.0 \mathrm{ml})$ of $0.5 \%$ hyperbaric bupivacaine combined with $0.4 \mathrm{ml}$ normal saline in Group $\mathrm{C}$ as a control group. On completion of spinal injection the patient was placed in the supine position with left uterine displacement. Oxygen $(3 \mathrm{~L} / \mathrm{min})$ was administered via facemask. Cardio respiratory parameters were monitored continuously and recordings were made every 5 minute till the end of surgery. Postoperatively 30 minutes interval up to 6 hour in recovery room. Intraoperatively and postoperatively incidence of bradycardia (heart rate $<50$ beats per minute) was treated with $0.6 \mathrm{mg}$ of injection atropine iv. Hypotension was defined as a decrease of systolic blood pressure by more than $30 \%$ from baseline or a fall below $90 \mathrm{mmHg}$ and was treated by increasing the rate of intravenous fluid administration, and by inj. mephentermine 3 to $6 \mathrm{mg}$ iv.

After delivery of the baby and clamping of the umbilical cord, a 10 I.U.of inj. oxytocin was given iv. APGAR score of all the babies with recordings at 1 and 5 minutes. Intraoperative and post delivery emetic symptoms till 6 hours were recorded by direct questioning by an anesthesiologist. Nausea was defined as subjective unpleasant sensation associated with awareness of the urge to vomit. Retching was defined as laboured spasmodic, rhythmic contractions of the respiratory muscles without the expulsion of gastric contents. Vomiting was defined as forceful expulsion of gastric contents from the mouth. Inj.ondansetron $4 \mathrm{mg}$. iv was administered as rescue antiemetic with the occurrence of two or more emetic symptoms. The details of any other adverse events due to study drug on mother such as hypotension, sedation, shivering, and respiratory depression were recorded.

\section{Statistical Analysis}

Statistical analysis was performed with SPSS Version 17.0 statistic software package. Data were expressed as means \pm standard deviation (SD). Comparisons between groups were performed with Student's t-test and $\chi^{2}$-test. A value of $p<0.05$ was considered statistically significant.

\section{Results and Discussion}

After the spinal anesthesia in parturients posted for cesarean section, the incidence of nausea-vomiting is as high as $66 \%^{10}$. Poor sensory component leading to visceral pain is one of the triggering factors for emesis alone. Bupivacaine is insufficient to provide complete analgesia in spite of high sensory block. Furthermore, the more higher the block, the more chances of hemodynamic compromise. Hypotension itself causes emesis due to hypoxia of CTZ. ${ }^{11}$

The incidences of emetic symptoms are more in parturient compared with non-parturient this is due to high level of progesterone that causes smooth muscle relaxation, decrease in gastrointestinal motility, and lower oesophageal sphincter tones. ${ }^{12}$ Prevention of PONV will improve patient satisfaction with their overall surgical experience, and it also lead to a more rapid resumption of their normal activities in early post discharge period. ${ }^{13}$

Table I and Table II shows distribution of patients according to demographic data and operative management in group $\mathrm{C}$ and group $\mathrm{M}$. Overall, every patient in two groups were compared with respect to age, weight, height, ASA status and gravida. Time taken and handling of viscera during cesarean section is more in multigravida with previous cesarean section which may trigger pain and emetic symptoms, thus distribution was made evenly in each group for gravida status. The patients were comparable with respect to duration of uterus exteriorized. As uterus exteriorization will lead to visceral traction, pain and emetic symptoms, we considered this parameter to compare amongst the group. ${ }^{11}$

Table III shows distribution of patients according to incidence of emetic symptoms, $30 \%$ of patients in control group had nausea as compared to $13.33 \%$ of patients in midazolam group. Similarly, $15 \%$ of the patients in control group had retching as compared to $1.66 \%$ in midazolam group. No patient in midazolam group had frank vomiting where as in control group, $18.33 \%$ of the patients had vomiting. The results of our study revealed that intrathecal midazolam decrease the incidence of intra operative and early post delivery emetic symptoms in comparison with control. While incidence of nausea-vomiting in control group was 
63.34\%, intrathecal midazolam $2 \mathrm{mg}$ reduced the incidence of emetic symptoms to $15 \%$. Rescue antiemetic was required in $7(11.67 \%)$ patients in the control group, however, the requirement was reduced to $2(3.33 \%)$ in the midazolam group. Midazolam as antiemetic acts by reducing synthesis, release and postsynaptic effect of dopamine at chemoreceptor trigger zone. ${ }^{14,15}$

There have been earlier studies for evaluating the efficacy of intrathecal midazolam in prevention of PONV. Suwalka et $\mathrm{al}^{16}$ evaluated the postoperative analgesic effect of intrathecal midazolam-lignocaine mixture in patients undergoing caesarean section and found that incidence of nausea and vomiting was less in midazolam group when compared to lignocaine group $(1: 8)$. Chattopadhyay et $\mathrm{a}^{14}$ also concluded that use of intrathecal midazolam decrease the incidence of postoperative nausea and vomiting. Prakash et $\mathrm{al}^{17}$ reported significantly lower incidence of nausea in intrathecal midazolam group compared to control group. Shahriari et $\mathrm{al}^{18}$ evaluated the efficacy and safety of bolus dose of midazolam $2 \mathrm{mg}$ iv and metoclopramide $10 \mathrm{mg}$ iv in reducing emetic symptoms during caesarean delivery under spinal anaesthesia and cited that the frequency of intraoperative nausea and vomiting was lower in the midazolam group compared with metoclopramide group (15\% versus $52.5 \%$ ). The results of our study are in agreement with these studies.

Table IV shows incidence of adverse effects amongst two groups. 6(10\%) patients in group C and
$3(5 \%)$ in group $\mathrm{M}$ had hypotension in our study which was not statistically significant $(\mathrm{p}=0.59)$. This could be because all patients in the present study were preloaded with $15 \mathrm{ml} / \mathrm{kg}$ of Ringer lactate and wedge was provided immediately after spinal block. Total intraoperative consumption of inj. mephentermine was similar in both the groups (Group C $-10.2 \pm 2.26 \mathrm{mg}$, Group M $-9.56 \pm 0.5 \mathrm{mg}$ ). None of the patients required vasopressors postoperatively. Other parameters such as pulse rate and respiratory rate remained stable intraoperatively as well as post-operatively in all the patients. Therefore, in this study, the low dose of intrathecal midazolzm did not have any deleterious cardiovascular effects on the parturients. Sedation was observed only in midazolam group in $4(6.66 \%)$ patients, they were drowsy, but arousable by verbal stimulation, so no treatment was required. Incidence of shivering was more in the control group $6(10 \%)$ compared to the midazolam group 2 (3.33\%). None of the patients in two groups developed any neurological deficits postoperatively. The results of our study are comparable to the observations in the earlier studies. $16,18,19$

Table $\mathrm{V}$ shows all the neonates had APGAR scores more than 8 at one and five minutes. It was revealed by the results of the current studies that low dose midazolam intrathecally had no detectable adverse impact on neonatal condition, which are in concordance with the results of other investigators. ${ }^{17,19,20}$

Table I: Demographic Data

\begin{tabular}{|l|c|c|c|}
\hline & Group C & Group M & p-value \\
\hline Age (Years) & $24.13 \pm 3.09$ & $24.56 \pm 2.44$ & $>0.05, \mathrm{NS}$ \\
\hline Height (Centimeters) & $157.06 \pm 2.88$ & $154.40 \pm 3.36$ & $>0.05, \mathrm{NS}$ \\
\hline Weight (Kilograms) & $61.88 \pm 5.98$ & $59.40 \pm 5.18$ & $>0.05, \mathrm{NS}$ \\
\hline ASA Status I/II $(\mathrm{n}=60)$ & $28 / 32$ & $29 / 31$ & $>0.05, \mathrm{NS}$ \\
\hline Primi/Multi Gravida $(\mathrm{n}=60)$ & $32 / 28$ & $34 / 26$ & $>0.05, \mathrm{NS}$ \\
\hline
\end{tabular}

Table II: Operative Management

\begin{tabular}{|l|c|c|c|}
\hline & Group C & Group M & p-value \\
\hline Duration of Surgery (Minutes) & $47.00 \pm 6.07$ & $48.4 \pm 5.56$ & $>0.05, \mathrm{NS}$ \\
\hline Uterus exteriorized (n) & $18(30 \%)$ & $17(28.33 \%)$ & $>0.05, \mathrm{NS}$ \\
\hline Duration of uterus exteriorized (Minutes) & $8.88 \pm 0.83$ & $10.0 \pm 1.22$ & $>0.05, \mathrm{NS}$ \\
\hline Mephenteramine Required(n) & $9(15 \%)$ & $6(10 \%)$ & $>0.05, \mathrm{NS}$ \\
\hline Mephenteramine Dose (Milligrams) & $8.66 \pm 2.34$ & $10.5 \pm 1.64$ & $>0.05, \mathrm{NS}$ \\
\hline
\end{tabular}

Table III: Distribution of patients according to incidence of emetic symptoms

\begin{tabular}{|l|c|c|c|c|}
\hline Emetic Symptoms & Group C & Group M & $\kappa^{2}$-value & p-value \\
\hline No nausea & $22(36.66 \%)$ & $51(85 \%)$ & 60.6 & $0.0001, \mathrm{~S}$ \\
\hline Nausea & $18(30 \%)$ & $8(13.33 \%)$ & 8.56 & $0.003, \mathrm{~S}$ \\
\hline Retching & $09(15 \%)$ & $1(1.66 \%)$ & 10.86 & $0.001, \mathrm{~S}$ \\
\hline Vomiting & $11(18.33 \%)$ & $0(0 \%)$ & 19.78 & $0.0001, \mathrm{~S}$ \\
\hline
\end{tabular}


Table IV: Incidence of adverse effects amongst two groups

\begin{tabular}{|l|c|c|}
\hline \multicolumn{1}{|c|}{ Adverse effects } & Group C & Group M \\
\hline Bradycardia & $0(0 \%)$ & $0(0 \%)$ \\
\hline Hypotension & $6(10 \%)$ & $3(5 \%)$ \\
\hline Shivering & $6(10 \%)$ & $2(3.33 \%)$ \\
\hline Sedation & $0(0 \%)$ & $4(6.66 \%)$ \\
\hline $\begin{array}{l}\text { Respiratory Depression/ Neurological } \\
\text { Deficit }\end{array}$ & $0(0 \%)$ & $0(0 \%)$ \\
\hline
\end{tabular}

Table V: Comparison of APGAR Scores

\begin{tabular}{|c|c|c|c|}
\hline APGAR score & Group C & Group M & p- value \\
\hline $1 \mathrm{~min}$ & $8.08 \pm 0.27$ & $8.05 \pm 0.21$ & $>0.05, \mathrm{NS}$ \\
\hline $5 \mathrm{~min}$ & $9.93 \underline{ \pm 0.25}$ & $9.9 \pm 0.3$ & $>0.05, \mathrm{NS}$ \\
\hline
\end{tabular}

\section{Conclusion}

The conclusion of our results is that intrathecal midazolam $2 \mathrm{mg}$ with $0.5 \%$ hyperbaric bupivacaine in the subarachnoid block significantly reduces the incidence of intraoperative and early postoperative nausea-vomiting in cesarean sections under spinal anesthesia, when compared to bupivacaine alone with no neonatal adverse effects.

\section{Limitation}

In our study we have not compared the efficacy of intrathecal midazolam with other commonly used and well established antiemetics. For assessment of neonatal outcome, neurobehavioral examination, neurologic and adaptive capacity score, umbilical blood gas analysis and acid base evaluation was not done.

\section{Source of Support: Nil}

Conflict of Interest: There are no conflicts of interest.

\section{References}

1. Aiono-Le TL, Butwick AJ, Carvalho B. A survey of perioperative anesthetics practices for caesarean delivery. Anesthesiology Research and Practice. 2009;1-7.

2. Lussos S, Bader A, Thornhill M, Datta S. The antiemetic efficacy and safety of prophylactic metoclopramide for elective caesarean delivery during spinal anaesthesia. Regional anesthesia.1992;17:126-30.

3. Balki M, Carvalho JC. Intraoperative nausea and vomiting during cesarean section under regional anesthesia. International journal of obstetric anesthesia. 2005;14:230-41.

4. Nortcliffe SA, Shah J, Buggy DJ. Prevention of postoperative nausea and vomiting after spinal morphine for caesarean section: Comparison of cyclizine, dexamethasone and placebo. British Journal of Anaesthesia 2003;90:665-70.

5. Mohamed F, Firas D, Riadh B, Walid D, Lasaad S and Abdelhamid K .Combined use of metoclopramide and dexamethasone as a prophylactic antiemetic in elective cesarean section under spinal anesthesia. Middle East Journal of Anesthesiology.2012;21(6):829-34.

6. Soreingam K, Singh T, Thokchom R, Singh Y, Meitei A and Singh S, Comparative study of intravenous ondansetron and intrathecal fentanyl for prevention of perioperative nausea and vomiting during caesarean delivery under spinal anaesthesia with hyperbaric bupivacaine. IOSR Journal of Dental and Medical Sciences.2017;16(4):22-6.

7. Kohno T, Wakai A, Ataka T, Ikoma M, Yamakura T, Baba $\mathrm{H}$ : Actions of midazolam on excitatory transmission in dorsal horn neurons of adult rat spinal cord.Anesthesiology 2006,104:338-43.

8. Di Florio T. The use of midazolam for persistent postoperative nausea and vomiting. Anaesth Intensive Care. 1992;20:383-6.

9. Senel AC, Mergan F. Premedication with midazolam prior to caesarean section has no neonatal adverse effects. Braz J Anesthesiol. 2014;64:16-21.

10. Biswas BN, Rudra A, Bose BK, Nath S, Chakrabarty S, Bhattacharjee S. Intrathecal fentanyl with hyperbaric bupivacaine improves analgesia during caesarean delivery and in early postoperative period. Indian $\mathbf{J}$ Anaesth. 2002;66:469-72.

11. Meshram S. Comparison of Intrathecal Fentanyl and Midazolam as an Adjuvant to Bupivacaine for Enhancing the Quality of Subarachnoid Block and thereby Preventing Nausea and Vomiting in Caesarean Delivery. Journal of Evidence Based Medicine and Healthcare.2016;3(98):5393-99.

12. Jabalameli M, Honarmand A, Safavi M, Chitsaz M. Treatment of postoperative nausea and vomiting after spinal anesthesia for cesarean delivery: A randomized, double-blinded comparison of midazolam, ondansetron, and a combination. Adv Biomed Res. 2012;1:2.

13. Butwick A. What's new in obstetric anesthesia in 2011? Reducing maternal adverse outcomes and improving obstetric anesthesia quality of care. Anesth Analg.2012;115:1137-45

14. Chattopadhyay A, Maitra S, Sen S. Midazolam in subarachnoid block as current evidence. ISRN Anesthesiol 2013;10:7.

15. Rodola F. Midazolam as an anti-emetic. European Review for Medical and Pharmacological Sciences. 2006;10:121-6.

16. Suwalka U, Patel J and Mehta K. Postoperative analgesia with intrathecal Midazolam in caesarean section deliveries. Indian Journal of Research and Reports in Medical Sciences. 2012;2(3):1-4.

17. Prakash S, Joshi N, Gogia AR, Prakash S and Singh R. Analgesic efficacy of two doses of intrathecal midazolam with bupivacaine in patients undergoing cesarean delivery. Regional Anesthesia and Pain Medicine. 2006;1(3):221-6.

18. Shahriari A,Khooshideh M, and Heidari M. Prevention of nausea and vomiting in caesarean section under spinal anaesthesia with midazolam or metoclopramide? Journal of Pakistan Medical Association.2009;59(11):756-9. 
19. Boules M, Botros J. Comparative study between the effect of intrathecal midazolam versus intrathecal midazolam plus magnesium sulphate on the efficacy and duration of analgesia in patients undergoing cesarean section. Ain-Shams Journal of Anaesthesiology. 2015;8(1):70.

20. Dodawad R, Sumalatha G, Pandarpurkar S and Jajee P. Intrathecal Midazolam as an Adjuvant in PregnancyInduced Hypertensive Patients Undergoing an Elective Caesarean Section: A Clinical Comparative Study. Anesthesiology and Pain Medicine. 2016;6(5):1-7. 